\title{
A relação entre a educação em saúde de pacientes com diabetes e os gastos em saúde no setor público
}

\author{
Bruno HELMAN ${ }^{(1)}$ \\ Lúcia Dias da Silva GUERRA ${ }^{(1)}$
}

${ }^{(1)}$ Faculdade de Saúde Pública, Universidade de São Paulo - USP, São Paulo, SP, Brasil.

Recebido: 28 jan 2019 Aceito: 10 fev 2019

Autor de correspondência: helman.bruno@gmail.com

Conflito de interesses: Os autores declaram não haver nenhum interesse profissional ou pessoal que possa gerar conflito de interesses em relação a este manuscrito.

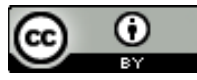

\section{Resumo}

O diabetes é uma pandemia global que atinge cerca de 425 milhões de pessoas. O Brasil possui uma das maiores prevalências do diabetes, sendo que ocupa a quarta posição entre pessoas adultas (20-79 anos) e a terceira posição entre jovens com menos de 19 anos com diabetes tipo 1. A Sociedade Brasileira de Diabetes - SBD declara que há mais de 13 milhões de brasileiros vivendo com a patologia, o que representa cerca de $7 \%$ da população (SBD, 2017). Contudo, não há qualquer distinção entre a população que possui diabetes tipo 1, tipo 2 ou até mesmo outro casos com menor prevalência, como "Lada" ou "Mody". Segundo a International Diabetes Federation - IDF, os cuidados em saúde referentes à essa doença, inclusive em países de baixo desenvolvimento, envolvem: acesso a medicação (insulina), automonitorização (teste de glicemia capilar), acompanhamento nutricional, prática de atividade física, acompanhamento psicológico e educação em diabetes. A Organização das Nações Unidas - ONU declarou em 2007, que o diabetes é um "desafio de saúde global" (ONU, 61/225), foi responsável por cerca de 1,5 milhão de mortes em 2012 (OMS, 2012), sem ao menos considerar os casos originados a partir de complicações do diabetes mellitus tipo 1 (DM1) e diabetes mellitus tipo 2 (DM2). Das mais de 422 milhões de pessoas com diabetes estima-se que cerca de $50 \%$ ainda não foi diagnosticada (IDF, 2015). Além das perdas humanas, o diabetes apresenta um altíssimo impacto econômico. Dados da American Diabetes Association (ADA), estimam que os gastos com os casos de diabetes diagnosticados foram de US\$ 327 bilhões em 2017 (ADA, 2017). Estudo realizado em 184 países do mundo, com adultos (20-79 anos), com diabetes estabeleceu que o custo global é de mais de US\$ 1 trilhão. Esse valor corresponde a quase $2 \%$ do PIB mundial. Bommer et al. (2017) concluíram que $2 / 3$ do valor total foram gastos diretos (cuidados médicos), enquanto $1 / 3$ foram gastos indiretos, como por exemplo, a perda de produtividade. Contudo, é extremamente difícil mensurar os custos diretos relacionados ao tratamento do diabetes e aqueles que são derivados do tratamento das suas complicações. A educação em saúde sobre diabetes é ferramenta fundamental do processo de manejo e autocuidado da pessoa que possui essa doença, mas muitas vezes é negligenciada pelos profissionais de saúde ou até mesmo pelos gestores tomadores de decisão. Ainda na primeira metade do século XX, Elliot P. Joslin, médico e fundador do centro de referência 
em diabetes que leva seu nome, já preconizava que "o paciente educado fica melhor". Essa linha de atenção de educação em saúde, que envolve a pessoa com diabetes, tornando-a protagonista do seu cuidado integral, tem ganho força no cenário mundial. Nos últimos cinco ano foi reconhecida tanto pela IDF quanto pela Organização Panamericana de Saúde - OPAS. Ainda com relação ao reconhecimento da importância da educação no processo de controle do diabetes, a OPAS - publicou em 2012 o caderno de orientações intitulado "Melhorias dos Cuidados Crônicos por meio das Redes de Atenção à Saúde" onde sugere um Modelo de Cuidados Crônicos - MCC, utilizado com êxito tanto em países desenvolvidos quanto nos países em desenvolvimento. Ele pressupõe que a atenção às doenças crônicas não transmissíveis (DCNTs) ocorra com base na orientação, na equidade com a participação do indivíduo, da família e da comunidade. Além disso, que fomente a preparação de recursos humanos na atenção às DCNTs e à qualidade de vida (SBD, 2017). É importante destacar que a Organização Mundial da Saúde (OMS) estabelece como "health education" o conjunto de ações desenvolvidas com intuito de ajudar comunidades e indivíduos a melhorarem sua saúde a partir do ganho de conhecimentos e/ou influência sobre suas atitudes. A limitada biografia existente sobre os custos do diabetes torna ainda mais complexa uma pesquisa que tem como objetivo entender a relação da educação em saúde do paciente com diabetes e os custos econômicos para a saúde pública. Objetivo: entender os custos econômicos para a saúde pública decorrentes da educação em saúde para pacientes com diabetes. Método: esse estudo é uma revisão integrativa com abordagem qualitativa, que busca entender o estado da arte sobre a relação da educação em saúde de pacientes com diabetes e os gastos em saúde com suas complicações, no setor público. Para isso, foi realizada a busca da literatura disponível sobre o tema, na base de dados PubMed. Como critério de inclusão, serão selecionados artigos científicos disponíveis na base de dados, no idioma português e inglês. Para a definição dos descritores de busca sobre o tema utilizou-se inicialmente, os DeCS (Descritores em Ciência da Saúde). Os principais descritores selecionados para a busca foram: educação em saúde, paciente, diabetes, gastos, setor público. Posteriormente, foi feita a pesquisa desses descritores na própria base de dados PubMed por meio do MeSH (Medical Subject Headings). A sintaxe final da busca foi (((PATIENT AND DIABETES MELLITUS)) AND (HEALTH EDUCATION OR HEALTH EXPENDITURE* OR COST)) AND PUBLIC SECTOR. Resultados: foram encontrados 72 estudos, a partir de uma análise preliminar observou-se que apenas dois estudos são nacionais e apenas um aborda exclusivamente o diabetes tipo 1, os demais não fazem essa distinção ou abordam exclusivamente o diabetes tipo 2 . Considerações finais: a partir dos dados, pôde-se observar que é um tema pouco abordado pela literatura o que pode ser uma evidência a pouca relevância dada à educação em saúde para população com diabetes pelos sistemas públicos ao redor do mundo.

Descritores: Diabetes Mellitus; Pacientes; Gastos em Saúde; Educação em Saúde. 